\section{MEASURING GROWTH}

One might have thought that something as basic as charting the growth of preterm babies might have been a settled issue by now, but as we all know, this is far from the case. We carried an important paper on updated birth weight centiles by Norris et $a l^{1}$ in November; now Pearson and Johnson in their Editorial revisit the difficulties inherent in constructing useful centile charts for preterm growth monitoring and make the case for the approach taken in constructing the INTERGROWTH 21st charts. This does not settle all controversies but should give readers some food for thought. Another aspect of "how" to chart growth is how often to weigh babies. Fenton et al make a compelling case for a routine interval of 5 to 7 days, which in practical terms might translate into 'once or twice a week'; of course, when weight measurement is part of fluid balance monitoring a baby may need to be weighed much more often. See page F120 and F218.

\section{MEASURING HEART RATE}

It is well known that relatively inexperienced staff managing neonatal resuscitation spend too much time staring at monitors and not enough looking at, and listening to, the baby. We have two contributions which emphasise the importance of the stethoscope. The first is a paper from Patel et al reporting a study in piglets which concludes that a combination of stethoscope, finger tips, pulse oximetry and ECG are needed if important diagnoses such as pulseless electrical activity are not to be missed. The second, a research letter from Treston et al, directly compared stethoscope, hand held ultrasound and ECG in terms of time to acquire an accurate estimate of heart rate. The stethoscope won because of the time taken to get ECG leads onto the baby's chest. See page F215 and F227

\section{STEROIDS, BREAST MILK AND BPD}

Hot on the heels of the network meta-analysis of steroids for preventing bronchopulmonary dysplasia by Zeng et $a l^{2}$ that we published in November, along with a provocative Editorial by Henry Halliday, we now have two further meta-analyses that relate to BPD. Huang et al synthesised the results of 5 randomised trials and 17 cohort studies examining the protective effects of feeding human breast milk as the whole or part of the neonatal diet and argue that the evidence is now strong that the more breast milk, the less BPD. Delara et al, in their meta-analysis of the efficacy of steroids applied directly to the lung, examined inhaled steroids, instilled steroids, and steroids instilled with a surfactant carrier. Inhalation, or instillation with surfactant, appeared most efficacious; the steroid of choice appeared to be budesonide. Fluticasone was also effective but there's only one RCT so far. See page F128 and F137

\section{CORD MANAGEMENT AT BIRTH}

The balance of advantages or disadvantages of early, delayed or 'physiological' cord clamping may well vary according to gestation at birth, and much has already appeared in FNN and elsewhere on this vexed topic. El-Naggar et al report their small RCT of cord milking versus immediate clamping of the cord in preterm babies of up to 30 weeks and 6 days at birth. The primary outcome was superior vena cava blood flow, and there were no between-group differences; the study was too underpowered for secondary outcomes (mortality, morbidity) to be able to draw any inferences. Alongside this is a fascinating review by Andrew Gill about the subject of postnatal cardiovascular adaptation in general: this should be mandatory reading for trainees in neonatal medicine as it would help to make up the large neonatal physiology knowledge deficit that senior colleagues commonly encounter. See page F145 and F220

\section{PARENTAL CONTACT AND NEONATAL OUTCOMES}

To the two papers this month that I am about to mention, I would add the meta-analysis in the Lancet that spells out the advantages to neonates of single-room care (Veenendaal et al, DOI 10.1016/ S2352-4642(18)30375-4) for reduction of sepsis rates, and enhancement of breast feeding.

In the wake of this it was interesting to read the paper by Cuttini et al that reports how rates of breastfeeding in Europe are associated with parental visiting policies: the more visiting, the more breast feeding. That units should have any kind of restrictive visiting policy at all will seem to some readers to emanate from the dark ages; such policies represent the very opposite of 'family integrated care' which is the topic of the Editorial this month by Harrison et al. Unlimited parental access is facilitated by, but does not require, single-room care. It's clear that there are massive variations between NICUs in their attitudes to parents; the key question of 'What is best for babies?' seems easily forgotten. See page F182 and F118.

\section{IODINATED CONTRAST AND MENB VACCINE}

Two papers that superficially have little in common except that they are useful. First, iodinated contrast. The iodine that inevitably goes into preterm babies who undergo contrast studies for long line placement has been a source of concern for some time, with anecdotal data suggesting the need for avoidance of iodinated contrast. To settle the argument, Rath et al conducted a formal randomised trial to establish whether the iodine story is truth or myth and have demonstrated that it is myth. Similarly, there have been concerns about the 4-component group $\mathrm{B}$ meningococcal vaccine $(4 \mathrm{CMenB})$ in relation to destabilising preterm babies after immunisation. Kent et al did not test this in a randomised trial, but in a surveillance study of 133 infants undertaken by Public Health England using historical controls from a previous RCT as a comparator. They were unable to demonstrate any association between 4CMenB administration and an increased rate of adverse effects, so although this does not have the rigour of an RCT it strongly suggests that $4 \mathrm{CMenB}$ is safe in routine use among preterm babies and demolishes another myth. See page F212 and F128.

\section{REFERENCES}

1 Norris T, Seaton SE, Manktelow BN, et al. Updated birth weight centiles for England and Wales. Arch Dis Child Fetal Neonatal Ed 2018;103:F577-82.

2 Zeng L, Tian J, Song F, et al. Corticosteroids for the prevention of bronchopulmonary dysplasia in preterm infants: a network meta-analysis. Arch Dis Child Fetal Neonatal Ed 2018;103:F506-11. 